\title{
Short Communication: Molecular characterization and blood hematology profile of dogs infected by Ehrlichia canis in Yogyakarta, Indonesia
}

\author{
YUSTINUS OSWIN PRIMAJUNI WUHAN ${ }^{1}$, ARIS HARYANTO ${ }^{2}$, IDA TJAHAJATI ${ }^{3, \bullet}$ \\ ${ }^{1}$ Faculty of Veterinary Medicine, Universitas Gadjah Mada. Jl. Fauna No. 2, Karangmalang, Sleman55281, Yogyakarta, Indonesia \\ ${ }^{2}$ Department of Biochemistry and Molecular Biology, Faculty of Veterinary Medicine, Universitas Gadjah Mada. J1. Fauna No. 2, \\ Karangmalang, Sleman55281, Yogyakarta, Indonesia \\ ${ }^{3}$ Department of Internal Medicine, Faculty of Veterinary Medicine, Universitas Gadjah Mada. J1. Fauna No. 2, Karangmalang, Sleman55281, \\ Yogyakarta, Indonesia.Tel: +62 274 560861, 560862, `email: ida_tjahajati@ugm.ac.id
}

Manuscript received: 4 May 2020. Revision accepted: 23 June 2020.

\begin{abstract}
Wuhan YOP, Haryanto A, Tjahajati I. 2020. Short Communication: Molecular characterization and blood hematology profile of dogs infected by Ehrlichia canis in Yogyakarta, Indonesia. Biodiversitas 21: 3242-3248. Ehrlichia canis is Gram-negative intracellular obligate bacteria that cause ehrlichiosis, a companion vector-borne disease is a potentially fatal disease that attacks dogs. The purpose of this study was to molecular characterize and determine the features of Ehrlichia-infected blood based on the amplification of the gltA gene in Ehrlichia infected dogs from Yogyakarta, Indonesia. Blood samples were collected from 51 dog patients from the Prof. Dr. Soeparwi Animal Hospital, animal clinics, and pet shops based on the anamnesis, clinical sign, and physical examination, followed by microscopic examination, routine hematology, PCR amplification, and DNA sequencing were carried out on the blood samples. Based on positive PCR amplification and blood hematology profile examination ehrlichiosis-positive in dogs showed that thrombocytopenia case was $82.3 \%$, anemia was $70.5 \%$, eosinopenia was $70.5 \%$, neutropenia was $29.4 \%$, monocytopenia was $23 \%$, leukopenia was $17 \%$ and lymphopenia was $11.7 \%$. Morulae of Ehrlichia sp.was not found in microscopic examination. Molecularly, detected of E. canis using the gltA gene showed that $34 \%$ of samples were positive results. Then 5 of positive Ehrlichia samples were DNA sequenced, they showed a high homology of $100 \%$ with Hat Yai isolates (KU765199.1). There was no genetic diversity between E. canis samples in Yogyakarta.
\end{abstract}

Keywords: Ehrlichia canis, gltA gene, hematology, molecular characterization

\section{INTRODUCTION}

Companion vector-borne disease (CVBD) is a growing health threat to the international community. This disease is transmitted by blood-sucking ectoparasites, namely ticks, fleas, mosquitoes, and flies which can transmit many dangerous pathogenic agents such as bacteria, protozoa, rickettsia, viruses or worms to dogs (Otranto et al. 2009). Canine monocytic ehrlichiosis is a potentially fatal disease that attacks dogs caused by Ehrlichia canis which is a Gram-negative intracellular obligate bacterium belonging to the family Anaplasmataceae, order Rickettsiales (Shukla et al. 2011). Other Ehrlichia species such as Ehrlichia ewingii and Ehrlichia chaffeensis may show clinical symptoms similar to E. canis, but E. canis is the main cause of ehrlichiosis in dogs transmitted through the Rhipicephalus sanguineus tick vector (Ramos et al. 2014). Tick-borne diseases are relevant for veterinarians in tropical and subtropical countries because of the spread of vectors and agents recognized as zoonoses (Arraga et al. 2014). Human infections have been reported in Venezuela (Perez et al. 2006) and in Panama (Daza et al. 2018). E. canis DNA has been detected in samples from human blood bank donors in Costa Rica (Bouza-Mora et al. 2016)
Canine monocytic ehrlichiosis (CME) is a contagious disease with a high incidence. Clinical signs of CME vary depending on the stage of the disease (acute, subclinical and chronic phases) which may be evident by fever, depression, lethargy, anorexia, lymphadenomegaly, splenomegaly, anemia, leukopenia, and thrombocytopenia (Singla et al. 2011; Tommasi et al. 2014; Piratae et al. 2019). E. canis can be detected for a short time in monocytes but cannot be found during the subclinical and chronic stages of infection. The stage of morula search in monocyte circulation is still a routine diagnostic method for ehrlichiosis cases. Reports about the incidence of ehrlichiosis in dogs in Indonesia are still limited. It was reported that the incidence of ehrlichiosis in dogs in the Animal Police Directorate of Security Agency (Baharkam) was 25 samples and $12 \%$ were reported positive. Five samples were taken from Atang Sendjaja Air Force (ATS), of which $40 \%$ were positively infected with E. canis (Hadi et al. 2016). There was also a report of an ehrlichiosis case in a Kintamani dog in Bali based on history, clinical symptoms, routine hematological results, and examination using a test kit which showed that the dog was E. canis positive (Erawan et al. 2017). Report on cases of ehrlichiosis disease detection in 1.785 dog patients at Jogja 
Animal Clinic using a kit test from January to September 2017 obtained a positive result of $7.63 \%$ (Nesti et al. 2018).

The incidence of ehrlichiosis in dogs tends to increase every year, while studies of ehrlichiosis disease caused by E. canis using hematological and molecular diagnosis methods are still limited, so this study is necessary. The aim of this study is to describe the ehrlichiosis blood and molecular characterization of E. canis using the gltA gene in dog patients in Yogyakarta, Indonesia so that the types of E. canis agents in Yogyakarta could be identified to help diagnose and determine appropriate therapy in cases of ehrlichiosis in dogs.

\section{MATERIALS AND METHODS}

\section{Anamnesis and physical examination}

Anamnesis is done by asking the animal owner to obtain information about the previous disease history related to tick infestations. Physical examination is done by examining mucous membranes or conjunctiva, body temperature, level of dehydration, appetite, hair condition (tick infestation), and general condition of the patient (Widodo 2011).

\section{Blood samples collection}

The study was conducted in March-November 2018. The blood samples were taken from 51 patients from the Prof. Soeparwi Animal Hospital (6 dogs), Jogja Animal Clinic (31 dogs), Satwa Kita Clinic (4 dogs), Djio Petshop (3 dogs), Naroopet shop (7 dogs). Blood samples were taken from dogs that showed clinical symptoms of ehrlichiosis. The blood samples from vena cephalica were taken $2 \mathrm{ml}$ from each dog (Nair et al. 2016).

\section{Blood smear microscopic examination}

Microscopic examination was carried out using a thin blood smear-staining method stained with $10 \%$ Giemsa solution and fixed with methanol for 5 minutes. Observation of the staining results was carried out using a light microscope (40-1000x magnification) (Ferrolho et al. 2016).

\section{Routine hematologic examination}

The routine hematologic examination was performed using a hematology analyzer that included examining the total number of erythrocytes, hemoglobin concentration, hematocrit value, platelet count, total leukocyte, neutrophils, eosinophils, basophils, lymphocytes and monocytes count (Parashar et al. 2016).

\section{DNA extraction}

The DNA extraction was carried out using the following materials: $20 \mu \mathrm{L}$ proteinase $\mathrm{K}, 200 \mu \mathrm{L}$ blood sample, $200 \mu \mathrm{L}$ GSB Buffer $\left(\right.$ Geneaid $\left.^{\circledR}\right), 200 \mu \mathrm{L}$ absolute Ethanol, $400 \mu \mathrm{L}$ W1 buffer solution (Geneaid ${ }^{\circledR}$ ), $600 \mu \mathrm{L}$ Wash Buffer $\left(\right.$ Geneaid $\left.^{\circledR}\right), \quad 100 \mu \mathrm{L}$ Elution Buffer $\left(\right.$ Geneaid $\left.^{\circledR}\right)$. DNA extraction was carried out by following the procedures determined by the Geneaid ${ }^{\circledR}$ company.

\section{DNA amplification}

DNA amplification was carried out by using a $25 \mu \mathrm{L}$ master mix $(2 \mu \mathrm{L}$ template DNA, $12 \mu \mathrm{L}$ PCR mix (KAPPABYOSTEMS $^{\circledR}$ ), $2 \mu \mathrm{L}$ Primer Forward, $2 \mu \mathrm{L}$ Primer Reverse, $6.5 \mu \mathrm{L}$ ddH2O2) Stages of amplification were performed based on the procedure of Geneaid company with initial temperature of denaturation $94{ }^{\circ} \mathrm{C}$ for 5 minutes, denaturation $94{ }^{\circ} \mathrm{C}$ for 45 seconds, annealing 56 ${ }^{0} \mathrm{C}$ for 45 seconds, extension $72{ }^{\circ} \mathrm{C}$ for 1 minute, and final extension $72{ }^{\circ} \mathrm{C}$ for 10 minutes. Primary nucleotide base sequence $\left(\mathrm{BIONER}^{\circledR}\right)$ of gltA gene of $E$. canis was Forward ECF primer: (5'-CAG GAG TAT CCT GA-3' (nucleotides 522-541) and Reverse ECR primer: (5'-GTT ACT TGG TTT TTC AAT TGC C-3' (nucleotide 1.010-1.031) with an amplification target of 510-bp (Fulvio et al. 2006).

\section{DNA electrophoresis}

The results of PCR product amplification were visualized on $1.5 \%$ agarose gel. $2 \mu \mathrm{L}$ of dye loading was mixed with $5 \mu \mathrm{L}$ of PCR product and slowly inserted into the well. Agarose gel electrophoresis was carried out for 45 minutes with a voltage of 100 volts.

\section{DNA sequencing and analysis}

Electrophoresis results that showed positive results were advanced to the sequencing stage. The PCR products used were $40 \mu \mathrm{L}, 50 \mu \mathrm{L}$ Primer Forward and $50 \mu \mathrm{L}$ Primer Reverse. The sequencing products were sent to PT. Genetica Science. The sequencing results were analyzed using the Basic Local Alignment Search Tool (BLAST) and compared with the gltA gene of E. canis from GenBank (Donkor et al. 2014). The phylogenetic analysis using Molecular Evolutionary Genetics Analysis (MEGA) software version 6.0 (Khan 2017).

\section{RESULTS AND DISCUSSION}

\section{Hematology profile of dog patients infected by Ehrlichia canis based on positive PCR}

The results of routine hematological examination on 51 blood samples of dog patients showed that 17 positive samples were infected with E. canis. The ehrlichiosis positive dogs experienced thrombocytopenia (82.3\%), anemia $(70.5 \%)$, eosinopenia $(70.5 \%)$, neutropenia $(29.4 \%)$, monocytopenia (23\%), leukopenia (17\%), and lymphopenia (11.7\%). This result is in line with research in Cebu which states that anemia and thrombocytopenia are the most common hematological results (Ybañez et al. 2018). The results of routine hematologic examinations in dog patients suffering from Ehrlichiosis are shown in Table 1.

Thrombocytopenia has been considered to be the most common and consistent hematological finding in dogs affected with CME as well as experimentally infected dogs (Asgarali et al. 2012; Silva et al. 2012; Milanjeet et al. 2014). Thrombocytopenia is the most common hematological disorder in CME cases that occurs in more than $80 \%$ of cases, regardless of the phase of the disease. However, CME should not be ruled out based solely on 
normal platelet counts (Sainz et al. 2015). Nonregenerative anemia, leucopenia, neutropenia, mild/moderate leukocytosis, neutrophilia, lymphopenia, or mild lymphocytosis are additional abnormalities (Castro et al. 2004). Anemia, which is usually normocytic, normochromic, and non-regenerative, suggesting a restricted or absent bone marrow response is a very important finding (Gaunt et al. 2010; Silva et al. 2012). Thrombocytopenia, anemia, hypoalbuminemia, increased alkaline phosphatase, decreased albumin, and globulin ratio are the most common findings in diagnosis of ehrlichiosis in dogs. This study illustrates the $100 \%$ prevalence of thrombocytopenia in E. canis seropositive dogs (Kottadamane et al. 2017). A similar study by Bhadesiya and Modi (2015) has proved that the mean of $\mathrm{Hb}, \mathrm{PCV}$, total erythrocyte count (TEC), total leukocyte count (TLC), and total platelet count significantly decreased in positive dogs. Decreased platelet count in blood circulation (thrombocytopenia) can be caused by a decrease in platelet production by bone marrow, abnormal distribution (platelets trapped in the enlarged spleen), dilution, and increased destruction of platelets (Stockham and Scott 2008). Hypoplastic condition is associated with a decrease in the number of neutrophil precursor cells in the marrow due to rickettsia (E. canis infection) in dogs and Ehrlichia risticii infection in horses (Mylonakis et al. 2010). The results of blood smear examination under the microscope did not found the formation of morules in monocytes. $E$. canis can be detected for a short time in monocytes but cannot be found during the subclinical and chronic stages of infection (Moriera et al. 2005). These results of the hematological profile study of dogs infected by E. canis were in line with another previous study conducted by Faizal et al. (2019), which used 51 dogs suspected of Anaplasma platys in Yogyakarta, Indonesia.

\section{DNA electrophoresis and sequence analysis}

The electrophoresis results of PCR products using 1.5\% agarose gel showed that there were 17 samples with positive results from a total of 51 samples. Positive results were indicated by the appearance of a $510 \mathrm{bp}$ amplicon band as shown in Figure 1. The results of thick and thin target bands visualization in a positive sample indicate the quality of isolated DNA influenced by sample conditions and DNA isolation procedures. Five samples from $17 \mathrm{E}$. canis positive samples were taken for sequencing analysis. Positive samples with the code E1 (KNP/A), E2 (KD/D), E3 (RSH/P), E4 (KHJ/D), and E5 (KHJ/E) shown in Figure 2.

Table 1. Hematology profile of dog patients infected by Ehrlichia canis based on positive PCR products

\begin{tabular}{|c|c|c|c|c|c|c|c|}
\hline \multirow[b]{2}{*}{ Sample code } & \multicolumn{7}{|c|}{ Hematology profile } \\
\hline & 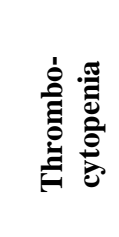 & & & 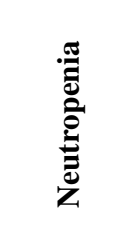 & 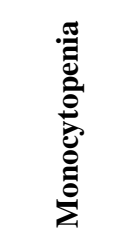 & 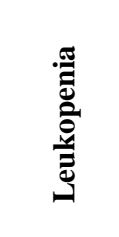 & 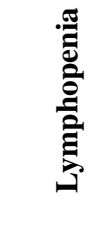 \\
\hline Doom KD/D & + & + & + & + & & & \\
\hline Hani KHJ/H & + & + & + & & & + & \\
\hline Avril KHJ/A & & + & + & & + & + & \\
\hline Audry KNP/A & + & + & & & & & \\
\hline Didot KHJ/D & + & + & + & + & & & \\
\hline Kopi KHJ/K2 & + & & + & + & & & \\
\hline Chocho KHJ/C & + & & + & + & & & \\
\hline Elby KHJ/E & + & + & + & + & & & \\
\hline Keyla KHJ/K3 & + & & + & & & & \\
\hline Picco RSH/P & + & + & & & + & + & \\
\hline Gobel KNP/G2 & & & + & & & & + \\
\hline Moi KNP/M & & + & + & & + & & \\
\hline Jacko KHJ/J2 & + & + & + & & + & & \\
\hline Nick KHJ/N & + & & & & & & + \\
\hline Von KHJ/V & + & + & + & & & & \\
\hline Mayo RSH/M & + & + & & & & & \\
\hline Ponny RSH/P & + & + & & & & & \\
\hline Precentage (\%) & $82.3 \%$ & $70.5 \%$ & $70.5 \%$ & $29.4 \%$ & $23.0 \%$ & $17.0 \%$ & $11.7 \%$ \\
\hline
\end{tabular}




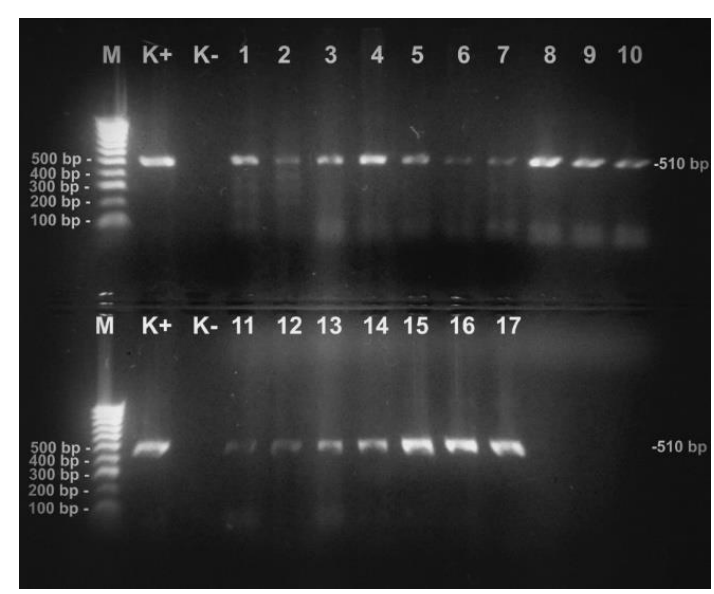

Figure 1. Electrophoresis of positive PCR products from dog patients infected by Ehrlichia canis. $\mathrm{M}=$ Marker DNA ladder 100 bp, $\mathrm{K}+=$ positive control, $\mathrm{K}-=$ negative control, No. $1-17=$ Sample with positive $\mathrm{PCR}$ products

Basic Local Alignment Search Tool (BLAST) analysis of the five sequence samples showed a red line in the sample which has very high homology (>200 nucleotides). Data sequences of gltA gene of $E$. canis from E1 (KNP/A), E2 (KD/D), E3 (RSH/P), E4 (KHJ/D), and E5 (KHJ/E) were aligned with sequence data from GeneBank E. canis Hat Yai (KU765199.1) isolates from Thailand (Liu et al. 2016). Multiple alignment results obtained 303 nucleotides. The similar sequence of nucleotide between the study samples and the sequence data of gltA gene of E. canis in GeneBank occurred in the nucleotide sequence 442-744 shown in Figure 3.

Nucleotide differences were analyzed between sequences of $E$. canis gltA genes from 5 samples; E1 (KNP/A), E2 (KD/D), E3 (RSH/P), E4 (KHJ/D), and E5 $(\mathrm{KHJ} / \mathrm{E})$ with sequence data of $E$. canis isolates Hat Yai Thailand (KU765199.1). The results of the analysis obtained values of nucleotide differences between 0-177 shown in Table 2. A value of 0 states that there is no nucleotide difference which means there are genotypic similarities shown between 5 samples with $E$. canis isolates Hat Yai Thailand (KU765199.1), E. canis Oklahoma from the United States and E. canis from Italy (AY647155.1). Significant differences in genotypic values are shown in Ehrlichia muris, Ehrlichia chaffeensis, Arkansas Wolbachia endosymbiont, Anaplasma phagocytophilum, Anaplasma platys, and Rickettsia asembonensis, namely $60,62,138,141,151$, and 154. The smaller nucleotide difference values indicate closer kinship due to closer genetic similarity.

The results of genetic distance analysis showed that $E$. canis samples E1 (KNP/A), E2 (KD/D), E3 (RSH/P), E4 (KHJ/D), and E5 (KHJ/E) with E. canis Hat Yai isolates from Thailand (KU765199.1), E. canis Oklahoma (AF304143.1) and E. canis from Italy (AY647155.1) have $100 \%$ homology shown in Table 3 . The genetic distance of E. canis coded E1 (KNP/A), E2 (KD/D), E3 (RSH/P), E4 (KHJ/D), and E5 (KH/E) in Yogyakarta with E. canis Hat Yai isolates (KU765199.1) is 0\%. Genetic distance is a

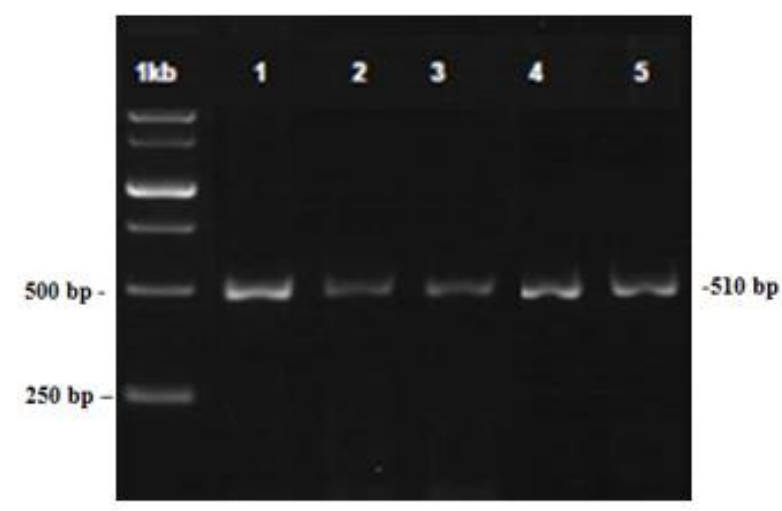

Figure 2. Electrophoresis of PCR products of the glt A gene in Ehrlichia canis after DNA purification process using DNA-ladder $250 \mathrm{bp}$.

genetic difference between species or between populations in one species. A small genetic distance (close to 0) indicates a close genetic relationship while a large genetic distance (approaching 1) indicates a distant genetic relationship. The results of genetic distance analysis showed that E. canis samples E1 (KNP/A), E2 (KD/D), E3 (RSH/P), E4 (KHJ/D), and E5 (KHJ/E) with E. canis Hat Yai isolates from Thailand (KU765199.1), E. canis Oklahoma (AF304143.1) from the United States (Inokuma et al. 2001) and E. canis from Italy (AY647155.1) have $100 \%$ homology. The following is Table 3. which shows the genetic distance of the E. canis gltA gene by the pdistance method.

The phylogenetic relationship of E. canis from Yogyakarta is homologous with E. canis isolates Hat Yai (KU765199.1) from Thailand, E. canis Oklahoma from the United States (AF304143.1) and E. canis citrate synthase ( $g l t A$ ) from Italy (AY647155.1) shown in Figure 4. The construction of phylogenetic tree using the neighborjoining method is constituted based on the distance matrix method. The distance method principle is the number of nucleotide differences between two DNA sequences showing the evolutionary distance that occurs; the smaller the nucleotide difference, the closer the kinship and the greater the nucleotide difference, the more distant the kinship. This can be seen in Figure 4; the samples in one clade show the closest kinship, while the distance of kinship is indicated by the genetic distance scale. Samples E1 (KNP/A), E2 (KD/D), E3 (RSH/P), E4 (KHJ/D), and E5 (KHJ/E) are related to E. canis isolates Hat Yai (KU765199.1) from Thailand, E. canis Oklahoma from the United States (AF304143.1) and E. canis citrate synthase (gltA) from Italy (AY647155.1) while distantly related to Ehrlichia chaffeensis and Ehrlichia muris.

The phylogenetic tree shows that from the analyzed $E$. canis nucleotide sequences, four main clades were formed. Clade I is E. canis Hat Yai isolates (KU765199), E1 (KNP/A), E2 (KD/D), E3 (RSH/P), E4 (KHJ/D), and E5 $(\mathrm{KHJ} / \mathrm{E})$, E. canis Oklahoma from the United States 
(AF304143.1) and E. canis citrate synthase (gltA) from Italy (AY647155.1), Clade II is Arkansas Ehrlichia chaffeensis and Ehrlichia muris, Clade III is Anaplasma phagocytophilum and Anaplasma platys, and Clade IV is Wolbachia endosymbiont and Rickettsia asembonensis. There is no genetic diversity in E. canis samples with codes E1 (KNP/A), E2 (KD/D), E3 (RSH/P), E4 (KHJ/D), and $\mathrm{E} 5(\mathrm{KHJ} / \mathrm{E})$. The phylogenetic relationship of E. canis from Yogyakarta is homologous with E. canis isolates Hat Yai (KU765199.1) from Thailand, E. canis Oklahoma from the United States (AF304143.1) and E. canis citrate synthase ( $g l t A)$ from Italy (AY647155.1).
There are variations in blood features in ehrlichiosis patients, namely thrombocytopenia, anemia, eosinopenia, neutropenia, monocytopenia, leukopenia, and lymphopenia. Molecular diagnosis of E. canis using the gltA gene obtained 17 positive results $(33.3 \%)$. Sequencing results showed no diversity of E. canis in Yogyakarta. The type of E. canis in Yogyakarta is homologous with the type of $E$. canis isolate Hat Yai Thailand (KU765199.1), E. canis Oklahoma from the United States of America (AF304143.1) and E. canis citrate synthase (gltA) from Italy (AY647155.1).

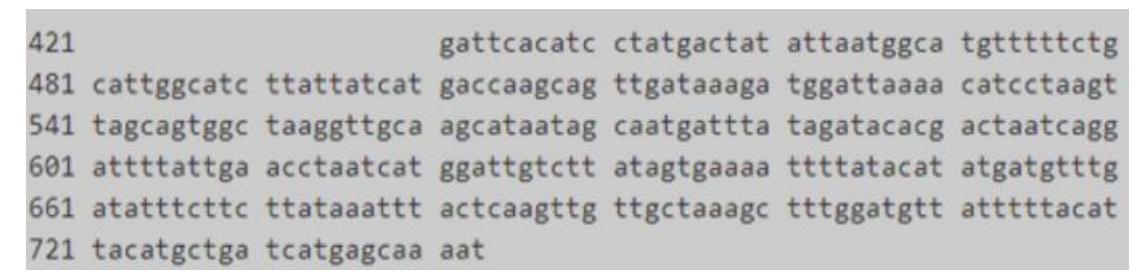

Figure 3. Sequencing products of gltA gene in Ehrlichia canis from dog patients

Table 2. Differences sequence of nucleotides Ehrlichia canis gen gltA sample with sequences from GenBank

\begin{tabular}{|c|c|c|c|c|c|c|c|c|c|c|c|c|c|c|}
\hline No. & Sample code & 1 & 2 & 3 & 4 & 5 & 6 & 7 & 8 & 9 & 10 & 11 & 12 & 13 \\
\hline 1 & KU765199.1_Ehrlichia_canis & & & & & & & & & & & & & \\
\hline 2 & E1 & 0 & & & & & & & & & & & & \\
\hline 3 & E2 & 0 & 0 & & & & & & & & & & & \\
\hline 4 & E3 & 0 & 0 & 0 & & & & & & & & & & \\
\hline 5 & E4 & 0 & 0 & 0 & 0 & & & & & & & & & \\
\hline 6 & E5 & 0 & 0 & 0 & 0 & 0 & & & & & & & & \\
\hline 7 & Ehrlichia_canis_Oklahoma & 0 & 0 & 0 & 0 & 0 & 0 & & & & & & & \\
\hline 8 & AY647155.1_Ehrlichia_canis & 0 & 0 & 0 & 0 & 0 & 0 & 0 & & & & & & \\
\hline 9 & Ehrlichia_chaffeensis_Arkansas & 62 & 62 & 62 & 62 & 62 & 62 & 62 & 62 & & & & & \\
\hline 10 & Ehrlichia_muris & 60 & 60 & 60 & 60 & 60 & 60 & 60 & 60 & 42 & & & & \\
\hline 11 & Anaplasma_platys & 151 & 151 & 151 & 151 & 151 & 151 & 151 & 151 & 154 & 147 & & & \\
\hline 12 & Anaplasma_phagocytophilum & 141 & 141 & 141 & 141 & 141 & 141 & 141 & 141 & 138 & 145 & 153 & & \\
\hline 13 & Wolbachia_endosymbiont & 138 & 138 & 138 & 138 & 138 & 138 & 138 & 138 & 139 & 135 & 159 & 158 & \\
\hline 14 & Rickettsia_asembonensis_ & 154 & 154 & 154 & 154 & 154 & 154 & 154 & 154 & 159 & 160 & 177 & 175 & 153 \\
\hline
\end{tabular}

Table 3. Genetic distance sequences of Ehrlichia canis gltA gene by p-distance method

\begin{tabular}{|c|c|c|c|c|c|c|c|c|c|c|c|c|c|c|}
\hline No. & Sample code & 1 & 2 & 3 & 4 & 5 & 6 & 7 & 8 & 9 & 10 & 11 & 12 & 13 \\
\hline 1 & KU765199.1_Ehrlichia_canis & & & & & & & & & & & & & \\
\hline 2 & E1 & 0.00 & & & & & & & & & & & & \\
\hline 3 & E2 & 0.00 & 0.00 & & & & & & & & & & & \\
\hline 4 & E3 & 0.00 & 0.00 & 0.00 & & & & & & & & & & \\
\hline 5 & E4 & 0.00 & 0.00 & 0.00 & 0.00 & & & & & & & & & \\
\hline 6 & E5 & 0.00 & 0.00 & 0.00 & 0.00 & 0.00 & & & & & & & & \\
\hline 7 & Ehrlichia_canis_Oklahoma & 0.00 & 0.00 & 0.00 & 0.00 & 0.00 & 0.00 & & & & & & & \\
\hline 8 & AY647155.1_Ehrlichia_canis & 0.00 & 0.00 & 0.00 & 0.00 & 0.00 & 0.00 & 0.00 & & & & & & \\
\hline 9 & Ehrlichia_chaffeensis_ĀArkansas & 0.11 & 0.11 & 0.11 & 0.11 & 0.11 & 0.11 & 0.11 & 0.11 & & & & & \\
\hline 10 & Anaplasma_phagocytophilum & 0.15 & 0.15 & 0.15 & 0.15 & 0.15 & 0.15 & 0.15 & 0.15 & 0.15 & & & & \\
\hline 11 & Ehrlichia_muris & 0.10 & 0.10 & 0.10 & 0.10 & 0.10 & 0.10 & 0.10 & 0.10 & 0.07 & 0.16 & & & \\
\hline 12 & Anaplasma_platys & 0.20 & 0.20 & 0.20 & 0.20 & 0.20 & 0.20 & 0.20 & 0.20 & 0.19 & 0.20 & 0.19 & & \\
\hline 13 & Wolbachia_endosymbiont & 0.14 & 0.14 & 0.14 & 0.14 & 0.14 & 0.14 & 0.14 & 0.14 & 0.14 & 0.15 & 0.14 & 0.20 & \\
\hline 14 & Rickettsia_asembonensis & 0.16 & 0.16 & 0.16 & 0.16 & 0.16 & 0.16 & 0.16 & 0.16 & 0.16 & 0.16 & 0.17 & 0.19 & 0.17 \\
\hline
\end{tabular}




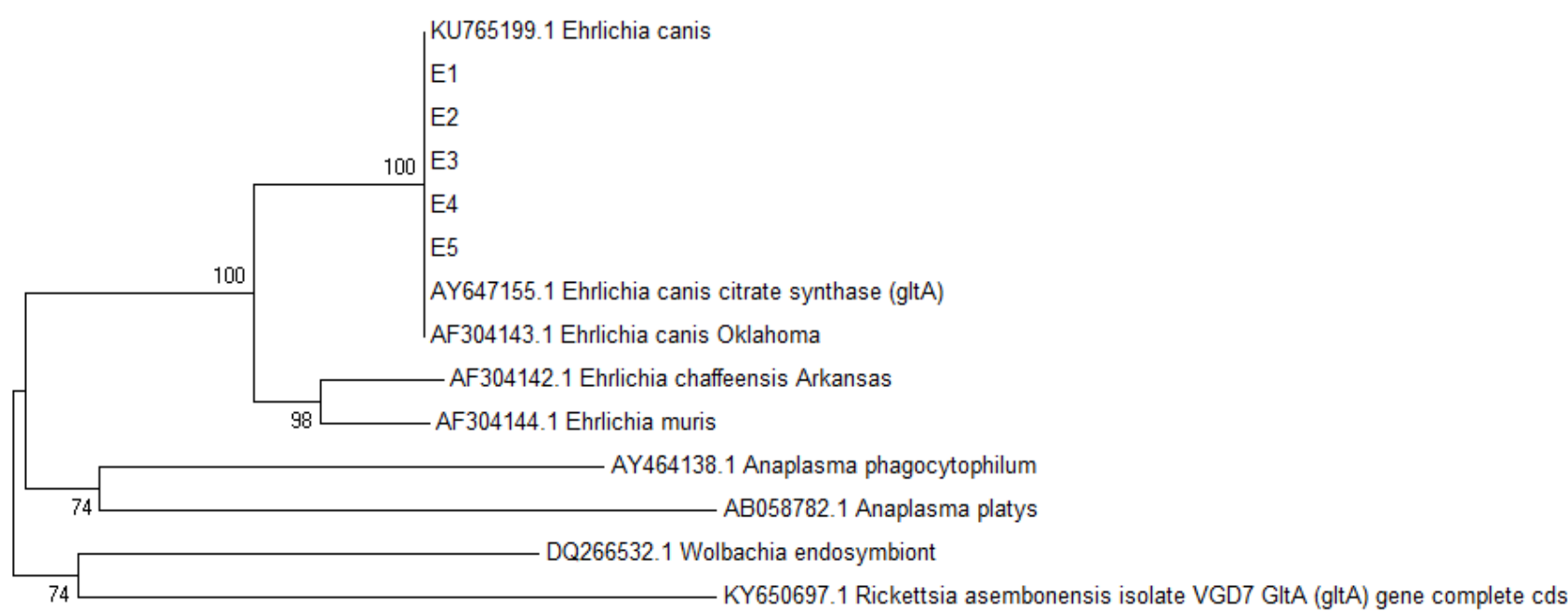

0.05

Figure 4. Phylogenetic tree of Ehrlichia canis

\section{ACKNOWLEDGEMENTS}

Thank you to the Dean of the Faculty of Veterinary Medicine, University of Gadjah Mada, Yogyakarta, Indonesia for funding the 2018 Faculty Competitive research with contract numbers: 1584/J01.1.22/HK4/2018 and the Chair of the Department of Biochemistry and the staff of the Biochemistry Laboratory of the University of Gadjah Mada who supported this research.

\section{REFERENCES}

Arraga CM, Qurollo BA, Parra OC, Berrueta MA, Hegarty BC, Breitschwerdt EB. 2014. Case Report: molecular evidence of Anaplasma platys infection in two women from Venezuela. Am J Trop Med Hyg 91 (6): 1161-1165.

Asgarali Z, Pargass I, Adam J, Mutani A, Ezeokoli C. 2012 Haematological parameters in stray dogs seropositive and seronegative to Ehrlichia canis in north Trinidad. Ticks Tick Borne Dis 3: $207-221$

Bhadesiya CM, Modi DV. 2015. Epidemiology of Rhipicephalus sanguineus and canine Ehrlichiosis in nine different localities. Int Agric Sc Vet Med 3 (1): 2320-3730.

Bouza-Mora L, Dolz G, Solórzano-Morales A, Romero-zu JJ, SalazarSánchez L, Labruna MB, Aguiar DM, Romero-Zuñiga JJ, SalazarSánchez L, Labruna MB, Aguiar DM. 2016. Novel genotype of Ehrlichia canis detected in samples of human blood bank donors in Costa Rica. Ticks Tick Borne Dis 8: 36-40.

Castro MB, Zacarias R, Padilha L, Alessi AC, Costa M. 2004 Experimental acute canine monocytic ehrlichiosis: clinicopathological and immunopathological findings. Vet Parasitol 119: 73-86.

Daza T, Osorio J, Santamaria A, Suárez J, Hurtado A, Bermúdez S. 2018. Caracterización del primer caso de infeción humana por Ehrlichia canis en Panamá. Rev Med Panama 36: 63-68.

Donkor ES Nicholas TKDD, Theophilis KA. 2014. Bioinformatics with basic local alignment search tool (BLAST) and fast alignment (FASTA). J Bioinform Seq Anal 6 (1): 1-6. DOI 10.5897/IJBC2013.0086
Erawan IGMK, Sumardik IW, Pemayun IGAGP, Ardana IBK. 2017. Laporan Kasus: Ehrlichiosis pada anjing Kintamani di Bali. Indonesia Med Veterinus 6 (1): 71-77 [Indonesian].

Faizal MD, Haryanto A, Tjahajati I. 2019. Diagnosis and molecular characterization of Anaplasma platys in dog patients in Yogyakarta area, Indonesia. Indon J Biotech 24 (1): 43-50.

Ferrolho J, Simpson J, Hawes P, Zweygarth E, Bell-sakyi L. 2016. Growth of Ehrlichia canis, the causative agent of canine monocytic ehrlichiosis, in vector and non-vector ixodid tick cell lines. Ticks Tick Borne Dis 7 (4):631-637. DOI: 10.1016/j.ttbdis.2016.01.013

Fulvio M, Di Martino B, Meridiani I, Bianciardi P. 2006. Direct identification of Ehrlichia canis by a novel polymerase chain reaction method and molecular analysis of the citrate synthase $(\mathrm{glt} A)$ gene from various Italian strains. J Vet Diagn Invest 18: 215-217.

Gaunt SD, Beall MJ, Stillman BA, Lorentzen L, Diniz PPVP, Chandrashekar R, Breitschwerdt EB. 2010. Experimental infection and co-infection of dogs with Anaplasma platys and Ehrlichia canis: hematologic, serologic and molecular findings. Parasite Vectors 3 (1): 33. DOI: $10.1186 / 1756-3305-3-33$

Hadi UK, Soviana S, Resa I, Pratomo C. 2016. Prevalence of ticks and tick-borne diseases in Indonesian dogs. Vet Sci Technol Technol 7: 3 DOI: 10.4172/2157-7579.1000330.

Inokuma H, Brouqui P, Drancourt M, Raoult D. 2001. Citrate synthase gene sequence: A new tool for phylogenetic analysis and identification of Ehrlichia. J Clin Microbiol 39 (9): 3031-3039.

Khan NT. 2017. MEGA - Core of Phylogenetic Analysis in Molecular Evolutionary Genetics. J Phylogenetics Evol Biol 5: 183. DOI: 10.4172/2329-9002.1000183

Kottadamane MR, Dhaliwal PS, Singla L Das, Bansal DK. 2017. Clinical and hematobiochemical response in canine monocytic ehrlichiosis seropositive dogs of Punjab. Vet World 10: 255-261.

Liu M, Ruttayaporn N, Saechan V, et al. 2016. Parasitology international molecular survey of canine vector-borne diseases in stray dogs in Thailand. Parasitol Intl 65 (4): 357-361.

Milanjeet, Singh H, Singh NK, Singh ND, Singh C, Rath SS. 2014. Molecular prevalence and risk factors for the occurrence of canine monocytic ehrlichiosis. Veterinarni Medicina 59 (3): 129-136.

Moreira SM, Passos LF. 2005. Detection of Ehrlichia canis in bone marrow aspirates of experimentally infected dogs Detecção de Ehrlichia canis em aspirados de medula óssea de cães experimentalmente infectados. Ciência Rural 35: 958-960.

Mylonakis ME, Day MJ, Siarkou V, Vernau W, Koutinas AF. 2010. absence of myelofibrosis in dogs with myelosuppression induced by Ehrlichia canis infection. J Comp Pathol 142 (4): 328-331. 
Nair ADS, Cheng C, Ganta CK, et al. 2016. Comparative Experimental Infection Study in Dogs with Ehrlichia canis, E.chaffeensis, Anaplasma platys and A. phagocytophilum. PLoS One 11 (2): e0148239. DOI: 10.1371/journal.pone.0148239

Nesti DR, Baidowi A, Ariyanti F, Tjahajati I. 2018. Deteksi penyakit zoonosis ehrlichiosis pada pasien anjing di klinik hewan jogja. J Nas Teknol 2: 191-197. [Indonesian].

Otranto D, Dantas-torres F, Breitschwerdt EB. 2009. Managing canine vector-borne diseases of zoonotic concern : part one. Trends Parasitol 25: $157-163$.

Parashar R, Kumar A, Ashish J. 2016. Evaluation of clinical, biochemical and haematological markers in natural infection of canine monocytic ehrlichiosis. J Parasit Dis 40 (4): 1351-1354.

Perez M, Bodor M, Zhang C, Xiong Q, Rikihisa Y. 2006. Human infection with Ehrlichia canis accompanied by clinical signs in Venezuela. Ann NY Acad Sci 117: 110-117.

Piratae S, Senawong P, Chalermchat P, Harnarsa W, Sae-chue B. 2019. Molecular evidence of Ehrlichia canis and Anaplasma platys and the association of infections with hematological responses in naturally infected dogs in Kalasin, Thailand. Vet World 12: 131-135.

Ramos RN, Stefania M, Giannelli A, et al. 2014. Detection of Anaplasma platys in dogs and Rhipicephalus sanguineus group ticks by a quantitative real-time PCR. Vet Parasitol 205 (1-2):285-288. DOI: 10.1016/j.vetpar.2014.06.023.
Sainz Á, Roura X, Miró G, Estrada-peña A, Kohn B, Harrus S. 2015. Guideline for veterinary practitioners on canine ehrlichiosis and anaplasmosis in Europe. Parasit Vectors 8: 75. DOI: 10.1186/s13071015-0649-0

Shukla S, Parihar S, Bariya S, Chaturvedi A. 2011. A clinic-pathological report of canine ehrlichiosis in a Doberman pinscher. Vet World 4 (8): 374-375.

Silva GCF, Benitez AN, Girotto A, Taroda A, Vidotto MC, Garcia JL, Freitas JC, Headley SA, Vidotto O. 2012. Occurrence of Ehrlichia canis and Anaplasma platys in household dogs from northern Parana. Revista Brasileira de Parasitologia Veterinaria 21: 379-385

Singla LD, Singh, H, Kaur, P, Singh, N.D, Singh, N.K. and Juyal, P.D. 2011. Serodetection of Ehrlichia canis infection in dogs from Ludhiana district of Punjab, India. J Parasit Dis 35: 195-198.

Stockham SL, Scott MA. 2008. Fundamentals of veterinary clinical pathology. Blackwell Publisher, Iowa, USA.

Tommasi AS, Otranto D, Furlanello T. 2014. Evaluation of blood and bone marrow in selected canine vector-borne diseases. Parasit Vectors 7: 534. DOI: 10.1186/s13071-014-0534-2

Widodo S, Sajuthi D, Choliq C, Wijaya A, Wulansari R, Lelana RPA. 2011. Diagnostik Klinik Hewan Kecil. IPB Press, Bogor. [Indonesian]

Ybañez RHD, Ybañez AP, Arnado LLA, Belarmino LMP. 2018. Detection of Ehrlichia, Anaplasma, and Babesia spp. in dogs in Cebu, Philippines. Vet World 11: 14-19. 